\section{Privileging the privileged: the public health focus on leisure time physical activity has contributed to widening socioeconomic inequalities in health}

\author{
Leon Straker (D) , ${ }^{1}$ Andreas Holtermann (D) , ${ }^{2}$ I-Min Lee (D), ${ }^{3}$ \\ Allard J van der Beek, ${ }^{4}$ Emmanuel Stamatakis (D) ${ }^{5}$
}

\section{SHORT MESSAGE}

Leisure-time physical activity focus is a social bias, which widens the socioeconomic gap in health

Physical activity researchers have a long tradition of concern for socioeconomic inequities in health. ${ }^{1}$ Non-occupational factors, such as welfare support and access to highquality healthcare, promote more

\footnotetext{
${ }^{1}$ School of Physiotherapy and Exercise Science, Curtin University, Perth, Western Australia, Australia ${ }^{2}$ Department of Musculoskeletal Disorders and Physical Workload, National Research Centre for the Working Environment, Kobenhavn, Denmark

${ }^{3}$ Department of Medicine, Harvard Medical School, Boston, Massachusetts, USA

${ }^{4}$ Public and Occupational Health, Amsterdam UMC VUMC Campus, Amsterdam, The Netherlands ${ }^{5}$ School of Health Sciences, University of Sydney, Sydney, New South Wales, Australia
}

Correspondence to Professor Leon Straker, School of Physiotherapy and Exercise Science, Curtin University, Perth, WA 6102, Australia; L.Straker@curtin.edu.au socioeconomic equality. Physical activity research can also be a major driver. We propose that designing the occupational physical activity of the less privileged to be health enhancing can help to reduce the socioeconomic health gap.

\section{IS THERE A SOCIAL BIAS IN CURRENT PHYSICAL ACTIVITY RESEARCH AND PRACTICE?}

Over the last 50 years researchers have built a compelling case that leisure time physical activity is an important pathway to good health. Based on this evidence, public health messaging has focused largely on increasing leisure time physical activity. ${ }^{2}$ However, this advice has been disproportionately taken up by the privileged higher socioeconomic groups. ${ }^{3}$ On the other hand, leisure time physical activity is decreasing in the lower socioeconomic groups. ${ }^{4}$
This phenomenon-limited time spent in leisure time physical activity in the lower socioeconomic group-is understandable. Compare these two sketches:

1. A high-earning professional living in a leafy suburb with a stay-at-home partner and safe access to a well-equipped gym, who easily finds opportunities to exercise after work and enjoys being active after sitting at work for much of the day.

2. A single parent looking after two young children and working three low-wage jobs, who is living in a small studio in an apartment block where it is unsafe to go outside after dark, and who has limited opportunities to exercise (and after paid work, looking after the house and caring for the children, is fatigued and just wants to rest).

\section{WHEN DID THE SHIFT TO LEISURE TIME} PHYSICAL ACTIVITY START?

The modern evidence base for the healthenhancing effects of physical activity began with the occupational physical activity studies of Morris et al..$^{5}$ Those studies arose from a concern about the socioeconomic health gradient-and an attempt to address it. ${ }^{1}$ Famously, the more active male bus conductors and postmen were at lower risk of heart disease than their less occupationally active colleagues. Morris and Paffenbarger's subsequent studies were among higher socioeconomic groups of civil servants and university alumni. 
In part, this was driven by available data to address their scientific questions, but also by a (perhaps incorrect) perception that job demands were unchangeable. As this privileged well-educated group had very little occupational physical activity, the focus of their (and most subsequent) studies shifted to leisure time physical activity, and its potential to compensate for the 'disadvantage' of insufficient occupational physical activity among higher socioeconomic groups. ${ }^{5}$

\section{WHAT WERE THE CONSEQUENCES OF THIS HISTORICAL SHIFT?}

Although the British civil servants and Harvard alumni were considered 'disadvantaged' in these studies by their lack of occupational physical activity, they were clearly privileged by most measures. The evident 'success' in promoting leisure time physical activity among higher socioeconomic groups may have contributed to widening the socioeconomic gap in health outcomes. Thus a (unintended) consequence of the social bias of focusing on leisure time physical activity is that physical activity research and practice has not had the impact it could have had on one of the most critical public health challengessocioeconomic inequalities in health.

Further, our understanding of what aspects of occupational physical activity are health-beneficial versus healthdetrimental is still not well advanced. ${ }^{6}$ Nor do we know what to advise workers with high occupational physical activity demands regarding their leisure time. For example, should they sit for recovery, or do high intensity interval training to enhance cardiovascular fitness, or do resistance exercise to enhance muscle strength and reduce osteopaenia in their leisure time? ${ }^{7}$

\section{CAN PHYSICAL ACTIVITY RESEARCH AND PRACTICE CORRECT THE SOCIAL BIAS?}

The early physical activity researchers recognised the societal trend towards employing progressively more and more people in occupations with little occupational physical activity. ${ }^{15}$ The large reductions in occupational physical activity over the last 50 years have been mainly driven by economic and technical factors. Perhaps adding to that trend, occupational health has reinforced reducing occupational physical activity with the goal to avoid fatigue, injury and musculoskeletal pain. Given the importance of health to productive work, and of work as a contributor to good health (which also allows people to stay in the workforce for longer) we argue that health should be a central consideration in the design of work-rather than just an inconvenient consequence. By designing jobs with the 'just right' amount and nature of physical activity (ie, the Goldilocks Work para$\operatorname{digm}^{8}$ ), we can correct socioeconomic biases and help reduce the socioeconomic inequity in health.

Twitter Leon Straker @Leon_Straker, Andreas Holtermann @profHoltermann and Emmanuel Stamatakis@M_Stamatakis

Contributors LS wrote the first draft of the manuscript. All authors contributed to the content of the manuscript and accepted the submitted version of the manuscript.

Funding The authors have not declared a specific grant for this research from any funding agency in the public, commercial or not-for-profit sectors.

Competing interests None declared.

Patient consent for publication Not required.

Provenance and peer review Not commissioned; externally peer reviewed.

(C) Author(s) (or their employer(s)) 2021. No commercial re-use. See rights and permissions. Published by BMJ.

\section{Check for updates}

To cite Straker L, Holtermann A, Lee I-M, et al. Br J Sports Med 2021;55:525-526.

Accepted 12 September 2020 Published Online First 1 October 2020

Br J Sports Med 2021;55:525-526.

doi:10.1136/bjsports-2020-103356

\section{ORCID iDs}

Leon Straker http://orcid.org/0000-0002-7786-4128 Andreas Holtermann http://orcid.org/0000-0003-48255697

-Min Lee http://orcid.org/0000-0002-1083-6907 Emmanuel Stamatakis http://orcid.org/0000-00017323-3225

\section{REFERENCES}

1 Paffenbarger RS, Blair SN, Lee I-M. A history of physical activity, cardiovascular health and longevity: the scientific contributions of Jeremy N Morris, DSC, DPH, FRCP. Int J Epidemiol 2001;30:1184-92.

2 Stamatakis E, Chaudhury M. Temporal trends in adults' sports participation patterns in England between 1997 and 2006: the health survey for England. Br J Sports Med 2008;42:601-8.

3 Beenackers MA, Kamphuis CBM, Giskes K, et al. Socioeconomic inequalities in occupational, leisure-time, and transport related physical activity among European adults: a systematic review. Int J Behav Nutr Phys Act 2012;9:116.

4 Seiluri T, Lahti J, Rahkonen 0, et al. Changes in occupational class differences in leisure-time physical activity: a follow-up study. International Journal of Behavioral Nutrition and Physical Activity 2011;8:14.

5 Morris JN, Heady JA, Raffle PAB, et al. Coronary HEARTDISEASE and physical activity of work. The Lancet 1953;262:1111-20.

6 Coenen P, Huysmans MA, Holtermann A, et al. Towards a better understanding of the 'physical activity paradox': the need for a research agenda. Br J Sports Med 2020;54:1055-7.

7 Holtermann A, Straker L, Lee I-M, et al. Long overdue remarriage for better physical activity advice for all: bringing together the public health and occupational health agendas. Br J Sports Med 2020;54:1377-8.

8 Straker L, Mathiassen SE, Holtermann A. The 'Goldilocks Principle': designing physical activity at work to be 'just right' for promoting health. Br J Sports Med 2018;52:818-9. 